\title{
Índice de mecanização de propriedades orizícolas no Rio Grande do Sul, Brasil ${ }^{1}$
}

\author{
Behavior of the index of mechanization in rice farms of Rio Grande do Sul, Brazil
}

\author{
José Fernando Schlosser ${ }^{2}$ Otávio Dias Da Costa Machado ${ }^{3}$ \\ Henrique Debiasi $^{4}$ Eder Dornelles Pinheiro ${ }^{5}$
}

\section{RESUMO}

\begin{abstract}
Caracterizada como atividade de alta expressão econômica no Rio Grande do Sul, a orizicultura é praticada de forma intensa, sobretudo na aplicação da mecanização. Tendo como objetivo diagnosticar o nível de mecanização $\left(\mathrm{kW} . h \mathrm{a}^{-1}\right)$, em função da área agrícola utilizada com arroz. (AARR) e da área agrícola total (AAGT), foi analisada uma amostra de 87 propriedades, que, dentre suas atividades, desenvolvem a orizicultura. Para a representação da escala das propriedades no índice estudado, foram aplicados oito estratos em função da área agrícola total das mesmas, sendo considerada a potência dos tratores agrícolas em atividade e as áreas produtivas declaradas. A participação diferenciada da área de cultivo de arroz nos diferentes estratos acarretou diferenças expressivas no indice de mecanização, quando analisadas a área de arroz e a área agrícola total. A estratificação mostrou-se eficiente na determinação da variação do índice de mecanização nos estratos estudados, ocorrendo diferença significativa apenas entre os estratos 3 (31 a 45ha) e 4 (46 a 90ha) e os estratos 6 (131 a 180ha) e 7 (181 a 400ha), quando relacionado o índice estudado à área orizícola, sendo representados por intervalos de classe eficientemente diferenciados para as demais médias.
\end{abstract}

Palavras-chave: índice de mecanização, arroz, máquinas agrícolas.

\section{ABSTRACT}

Characterized as activity of high economic expression in Rio Grande do Sul, Brazil, the rice production is practiced in an intense way, above all in the applied mechanization. Having as objective to diagnose the mechanization level $(\mathrm{kW} / \mathrm{ha})$, in function of the agricultural area used with rice (AARR) and of the total agricultural area (AAGT), a sample of 87 properties, that among amoung their activities develop the rice production, was analyzed. For the representation of the scale of the properties in the studied index, 8 strata were applied regarding the total agricultural area of the same ones, being considered for the available potency the agricultural tractors in activity and the declared productive areas. The differentiated participation of the area of cultivation of rice in the different strata carted in expressive differences of the mechanization index, when analyzed the area of rice and the total agricultural area. The bedding was shown efficient in the determination of the variation of the mechanization index along the studied strata, having significant difference only between the strata 3 (31 a 45ha) and 4 (46 a 90ha) and the strata 6 (131 a 180ha) and 7 (181 a 400ha), when related the index studied to the area of rice, being represented by intervals of class indeed differentiated for the other averages.

Key words: mechanization index, rice production, agricultural machinery.

\section{INTRODUÇÃO}

Podendo ser caracterizada como uma atividade de alta expressão no Rio Grande do Sul, a orizicultura é uma das atividades agrícolas de maior destaque em diversas regiões do Estado. Seu alto nível de participação na renda de diversos municípios evidencia a grande importância econômica e social desta cultura (COGO \& VELHO, 1995). Profundas mudanças foram absorvidas pela orizicultura, em função das alterações ocasionadas pela economia nos últimos anos. Atualmente, sob uma grande redução na margem de lucro, em função do aumento

\footnotetext{
${ }^{1}$ Artigo científico extraído da dissertação do segundo autor.

${ }^{2}$ Engenheiro agrônomo, Doutor, Professor Titular do Departamento de Engenharia Rural, Centro de Ciências Rurais (CCR), Universidade Federal de Santa Maria (UFSM), 97015-900, Santa Maria, RS, Brasil. E-mail: schlosse@ccr.ufsm.br. Autor para correspondência. ${ }^{3}$ Engenheiro Agrônomo, MSc.

${ }^{4}$ Engenheiro Agrônomo, MSc., Pesquisador da Fepagro, São Gabriel, RS.

${ }^{5}$ Acadêmico do Curso de Agronomia, CCR, UFSM.
} 
progressivo do preço dos insumos e da diminuição do preço recebido pelo produto, a atividade encontra-se ávida por informações que possibilitem seu melhor desempenho e um retorno econômico mais elevado (CENTENO, 1996). Tendo em vista o caráter de dependência mercadológica dos inputs e outputs produtivos, para que se possa alcançar maior renda, e redução de custo, é necessário emprego de técnicas eficientes, de maneira a aumentar a renda envolvida nesse processo, sobretudo com a otimização do uso do parque de máquinas agrícolas e da potência disponível, representada, principalmente, pelos tratores agrícolas utilizados. Segundo MELLO (1996), estudos dessa magnitude adquirem grande importância por influenciar um dos custos mais expressivos na produção orizícola, ou seja, da mecanização agrícola, potencializando os resultados dessa atividade agrícola. A utilização das relações de potência e área mostra um parâmetro de fundamental importância para o conhecimento da estrutura produtiva das propriedades agrícolas, e o conhecimento de sua distribuição real só é permitido perante a coleta de dados a campo (INCATEMA, 1996).

Com o objetivo de estudar a intensidade do uso da potência, a partir dos tratores e das áreas agrícolas amostradas, avaliou-se o índice de mecanização (kW/ha), em 8 estratos distintos da área agrícola total das propriedades. Devido ao fato da concentração da maquinaria nas atividades da lavoura orizícola em determinadas épocas do ano, a relação de potência e área foi estabelecida a partir da área de arroz (AARR), enquanto que, para a totalidade dos cultivos agrícolas, a mesma foi estudada em função da área agrícola total (AAGT).

\section{MATERIAL E MÉTODOS}

A amostragem utilizada foi a aleatória simples, em 87 propriedades rurais que, dentre suas atividades, desenvolvem a orizicultura, distribuídas ao acaso na região central do Estado. As informações foram obtidas através de questionários, aplicados diretamente no campo, onde se determinou a quantidade e a especificação dos tratores (marca, modelo, ano de fabricação, ano de aquisição e estado geral de manutenção) e o planejamento das operações mecanizadas em cada propriedade. Outras informações técnicas como a potência dos tratores agrícola foi obtida em material técnico disponível. O uso de questionários, retratando as características analisadas diretamente na propriedade e permitindo a expressão individual dos agricultores, bem como o contato direto do técnico, afirmam a veracidade das informações obtidas (BILLER \& OLFE, 1986; INCATEMA, 1996). Para a estratificação das propriedades, importante ferramenta no conhecimento do índice de mecanização em função das variações de escala, foi aplicado o método descrito por SCHEAFFER et al. (1996), segundo o autor o mais eficiente para a estratificação de uma amostra obtida aleatoriamente.

Para a análise estatística das informações foi aplicada a regressão através do programa Microsoft EXCEL $^{\circledR}$, enquanto que para o contraste das médias dos estratos aplicou-se o teste de comparações múltiplas de Kruskal-Wallis (SIEGEL, 1975).

\section{RESULTADOS E DISCUSSÃO}

O índice de mecanização comportou-se diferentemente em função da escala de produção (estrato) considerada, indicando maior intensidade de uso da potência em menores áreas (Tabela 1 e Figura 1). Com o aumento da área cultivada, ocorre a diluição da potência, o que representa um melhor aproveitamento do investimento imobilizado na compra de tratores agrícolas e que pode resultar em maior rentabilidade econômica. Entretanto, o maior índice de mecanização dos produtores menores faz com que estes adquiram maior capacidade de trabalho dos conjuntos mecanizados, permitindo-lhes trabalhar suas áreas em tempo relativamente menor e com maiores cuidados, o que condiz com a necessidade de obtenção de maiores produtividades, visto possuírem menores áreas agrícolas. Ainda conforme a figura 1, verifica-se que a redução inicial do índice de mecanização é superior considerando-se a área de arroz, comparativamente à área agrícola total. Isto pode ser explicado pelo fato da diversidade dos cultivos em número e área acarretar em maior variabilidade no índice de mecanização, quando são analisados estratos maiores.

A participação relativa da área de cultivo de arroz, em função da área agrícola total, é mais representativa nas escalas menores. Enquanto que para as áreas de até 90 ha sua participação foi de $78 \%$, para as áreas com mais de 90 ha, esta foi de $63 \%$ da área agrícola total. Para as áreas de 46 a 90 ha, atinge a maior participação relativa (90\%), o que acarreta a menor diferença entre o índice de mecanização para a área de arroz e área agrícola total. Em situação oposta, encontra-se o estrato 7 (181-400 ha), no qual a representatividade de outras áreas agrícolas alcança maior expressão, resultando um índice maior, porém não diferente do anterior. 
Tabela 1 - Número de amostras, área média e índice de mecanização da área agrícola total das propriedades analisadas e da cultivada com arroz, em função dos estratos aplicados.

\begin{tabular}{|c|c|c|c|c|c|c|c|}
\hline \multicolumn{2}{|r|}{ Estratos } & \multirow{2}{*}{$\begin{array}{c}\text { Número } \\
\text { de } \\
\text { amostras }\end{array}$} & \multicolumn{3}{|c|}{ Área de arroz (AARR) } & \multicolumn{2}{|c|}{ Área agrícola total (AAGT) } \\
\hline $\mathrm{N}^{\mathrm{o}}$ & $\begin{array}{l}\text { Limites } \\
\text { (ha) }\end{array}$ & & $\begin{array}{l}\text { Área } \\
\text { média } \\
\text { (ha) }\end{array}$ & $\begin{array}{l}\text { Partici- } \\
\text { pação } \\
(\%)^{*}\end{array}$ & $\begin{array}{c}\text { Índice de } \\
\text { mecanização } \\
(\mathrm{kW} / \mathrm{ha})^{* *}\end{array}$ & $\begin{array}{l}\text { Área } \\
\text { média } \\
\text { (ha) }\end{array}$ & $\begin{array}{c}\text { Índice de } \\
\text { mecanização } \\
(\mathrm{kW} / \mathrm{ha})^{* *}\end{array}$ \\
\hline 1 & 1 a 15 & 16 & 8,88 & 75 & $7,82 \mathrm{a}$ & 11,81 & $5,32 \mathrm{a}$ \\
\hline 2 & 16 a 30 & 11 & 17,18 & 73 & $6,18 b$ & 23,55 & $4,14 \mathrm{~b}$ \\
\hline 3 & 31 a 45 & 11 & 28,91 & 74 & $4,47 \mathrm{c}$ & 39,00 & $3,12 \mathrm{c}$ \\
\hline 4 & 46 a 90 & 11 & 56,18 & 90 & $3,97 \mathrm{c}$ & 62,36 & $3,55 \mathrm{~d}$ \\
\hline 5 & 91 a 130 & 8 & 77,13 & 67 & $3,55 \mathrm{~d}$ & 115,50 & $2,31 \mathrm{e}$ \\
\hline 6 & 131 a 180 & 10 & 94,50 & 64 & $3,34 \mathrm{e}$ & 147,50 & $1,83 \mathrm{f}$ \\
\hline 7 & 181 a 400 & 10 & 136,70 & 59 & $4,97 \mathrm{e}$ & 233,00 & $1,29 \mathrm{~g}$ \\
\hline 8 & $>400$ & 10 & 421,80 & 62 & $1,96 \mathrm{f}$ & 684,20 & $0,66 \mathrm{~h}$ \\
\hline \multicolumn{2}{|c|}{ Total (média) } & 87 & $(105,16)$ & $(70)$ & $(4,53)$ & $(164,62)$ & $(2,78)$ \\
\hline
\end{tabular}

* Participação relativa da área cultivada com arroz, em função da área agrícola total do estrato.

** Médias seguidas pela mesma letra não diferem pelo teste de comparações múltiplas de Kruskal-Wallis, ao nível de 5 \% de probabilidade.

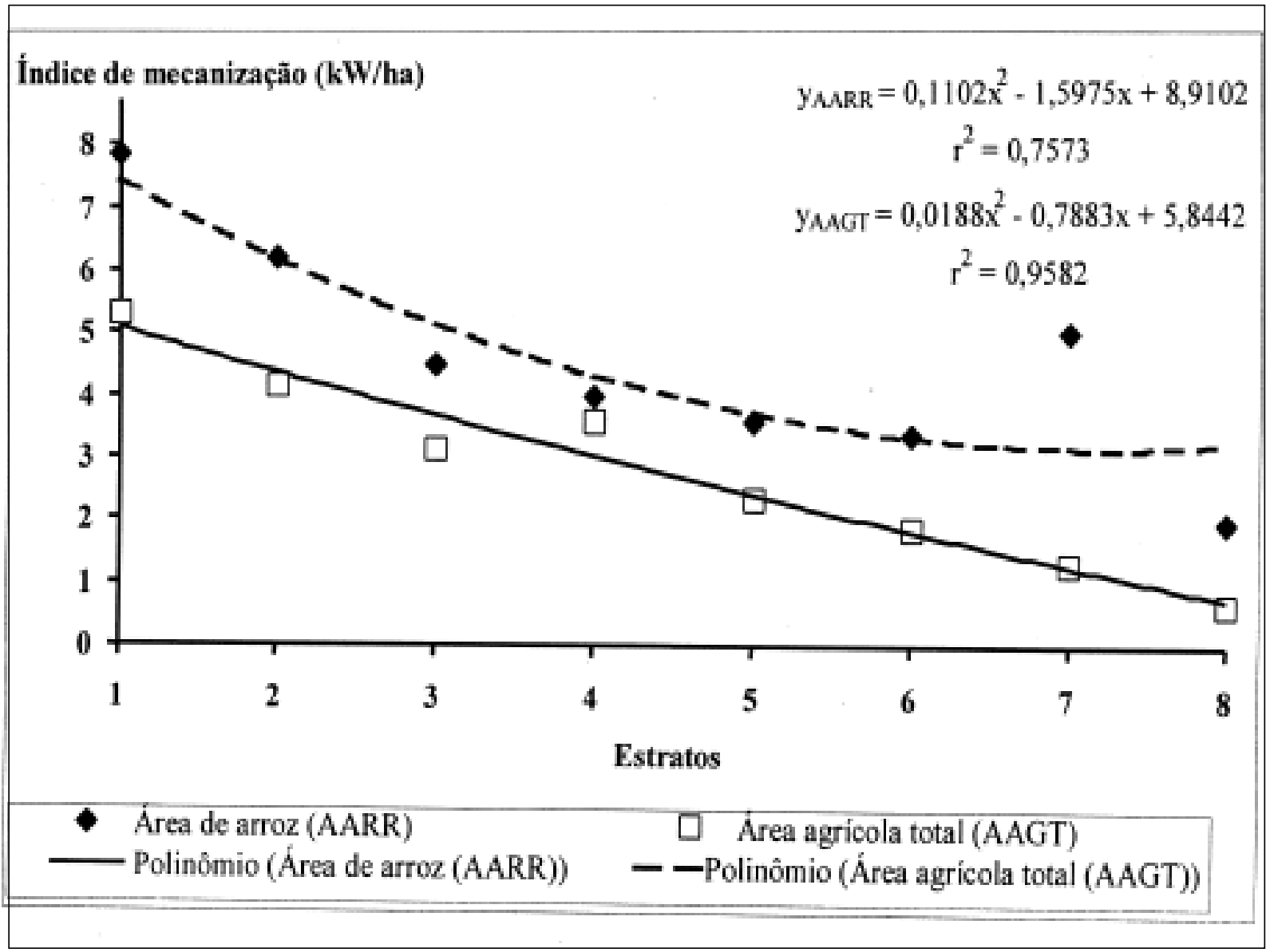

Figura 1 - Índice de mecanização em função da área de arroz e da área agrícola total.

Ciência Rural, v.34, n.3, mai-jun, 2004. 
Levando-se em consideração a área agrícola total, todos os estratos de área diferiram no que se refere ao índice de mecanização. Já para a área agrícola utilizada com arroz, houve semelhança entre os estratos 3 (31-45ha) e 4 (4690ha), bem como entre os estratos 6 (131-180 ha) e 7 (181-400ha).Isso foi devido à estratificação adotada, cujos intervalos de classe foram eficientes para a delimitação da variação do índice de mecanização, em função da escala das propriedades amostradas.

\section{CONCLUSÃO}

O índice de mecanização foi menor para as propriedades com maior área agrícola total e maior área de arroz. A maior disponibilidade de potência de tratores agrícolas nas propriedades de pequena área, evidenciada pelo seus altos índices de mecanização, demonstra menor distribuição do investimento na unidade de área, permitindo, entretanto, maior cuidado no trabalho e menor tempo para a realização das operações agrícolas. A orizicultura representa a principal atividade econômica nas menores propriedades, diminuindo sua expressão com o aumento de área e diversidade de cultivos.

\section{REFERÊNCIAS BIBLIOGRÁFICAS}

BILLER, R.H.; OLFE, G. The collecting of data on tractor use by questionnaires and by automatic data recording. Journal of Agricultural Engeneering Research, v.34, p.219-227, 1986.

CENTENO, A. Mecanização agrícola da lavoura arrozeira desafios e oportunidades. In: WORKSHOP SOBRE MECANIZAÇÃO AGRÍCOLA NA REGIÃO DO CLIMA TEMPERADO, 2., 1996, Pelotas. Anais... Pelotas : UFPel, 1996. p.93-94.

COGO, C.; VELHO, V. Diagnóstico setorial da orizicultura no RS: principais problemas e alternativas de soluções. Porto Alegre: Associação dos Municípios da Fronteira Oeste, 1995. $173 \mathrm{p}$.

INCATEMA, INGENIEROS Y SERVICIOS, S.L. Analisis del parque nacional de tractores agricolas. Madrid, 1996. $98 \mathrm{p}$.

MELLO, I. Desafios da mecanização na cadeia do arroz irrigado. In: WORKSHOP SOBRE MECANIZAÇÃO AGRÍCOLA NA REGIÃO DO CLIMA TEMPERADO, 2., 1996, Pelotas, RS. Anais... Pelotas : UFPel, 1996. p.87-90.

SIEGEL, S. Estadística no paramétrica aplicada a las ciências de la conducta. México : Editorial Trillas, 1975. 346p.

SCHEAFFER, R.L.; MENDEHALL III, W.; OTT, R.L. Elementary survey sampling. 5.ed. Belmont : Duxbury, 1996. 501p. 